\title{
Manufacturing and Properties of a Large Alloy 706 Dise Made by the Open Die Forging Process
}

\author{
K.H. Schönfeld*. B. Donth*, M.G. Cambi**, S.V. Thamboo**, M.P. Manning** \\ *Saarschmiede, Volklingen, Germany \\ **GE Power Systems, Schenectady, New York. USA
}

\begin{abstract}
Nickel base alloy 706 has extensive application history for rotating parts in land based gas turbines combining high strength and toughness over the whole range of the service temperatures. This material is typically finish forged in a closed die press. The size of parts needed for the land-based gas turbines is very large requiring the use of the largest forging presses in the world. Finish forging of alloy 706 and other nickel-based alloys for rotating parts in gas turbines require homogenous structure and properties throughout the forging. Many experts considered that open die forging process would not be able to achieve such uniformity. An experiment was done to determine if a well-controlled open die forging process could achieve the necessary uniformity in microstructure and properties for a large gas turbine part made of alloy 706 .
\end{abstract}

This paper will describe the details of the forging and heat treatment process. Results of mechanical tests and metallographic examination will be also discussed. Issues with process control and repeatability for open die forging are also discussed.

\section{Introduction}

The nickel-based alloy 706 is used for the turbine rotor of General Electric 's F class gas turbines (see Figure 1). It is a very suitable alloy for this application because of its high temperature capabilities ${ }^{\prime}$. Process development at General Electric and its suppliers has made it an alloy that can be melted into large ingots without any segregation problems.

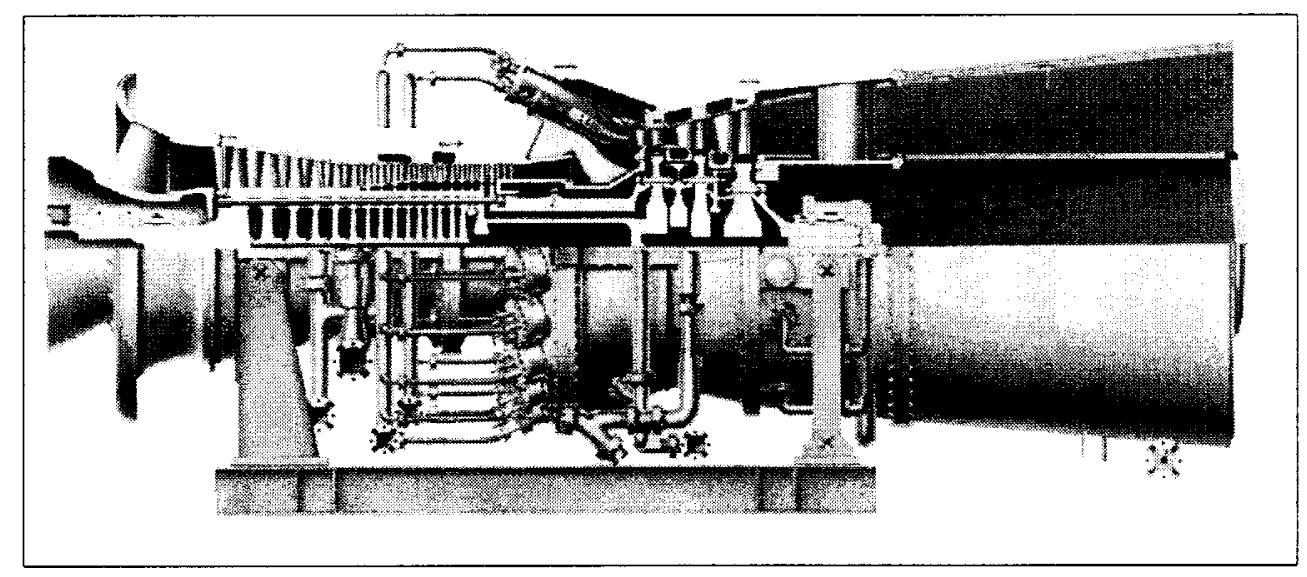

Figure 1 - Schematic of GE 7F Gas Turbine 
The forging process for this alloy for turbine rotor application requires press forging on closed die type hydraulic press. This is required because rotating parts need to have perfectly axisymetric microstructure and mechanical properties. Open die processes are expected to have problems achieving such uniformity. Therefore currently all 706 forgings for the $F$ class machines are made by the closed die forging presses. But the size of these forgings requires very large hydraulic presses. There are a limited number of such presses in the world. GE has experienced a big increase in orders for their $\mathrm{F}$ class machines because of the energy crisis. This sub size trial on open die forging of alloy 706 turbine component was made to explore this process as a way of relieving the capacity constraints of current presses.

\section{Manufacturing Process}

The disk was forged from an $810 \mathrm{~mm}$ (31.89 in) ingot produced by triple melting (VIM-ESR$\mathrm{VAR}$ ). The ingot was homogenized and converted to billet by double upset and drawing on a 6000 metric ton press. Cross sectional slices were removed from top and bottom ends to check ingot quality. Etching was performed to reveal macrosegregation, freckles or other melt related defects.

The disk forging was performed using incremental steps at $1050^{\circ} \mathrm{C}\left(1922^{\circ} \mathrm{F}\right)$. The billet was upset approximately $2: 1$ in one stroke to $1100 \mathrm{~mm}$ dia. X $660 \mathrm{~mm}(43 \mathrm{X} 26 \mathrm{in})$. This was followed by a series of passes consisting of multiple strokes to step across the face of the disk. The disk was reheated to $1050^{\circ} \mathrm{C}$ between passes. The disk was also rotated $90^{\circ}$ between passes to eliminate structural gradients that may be caused by tool orientation and ensure a fine and homogeneous grain structure. The finished forging dimensions were $1490 \mathrm{~mm}$ dia. X $373 \mathrm{~mm}$ (58.66 X $14.69 \mathrm{in})$.

The disk was machined prior to quality heat treatment for getting defined geometry and a proper surface to prevent cracking. The heat treatment included both solution and aging cycles. The solution was carried out holding at $980^{\circ} \mathrm{C}\left(1796^{\circ} \mathrm{F}\right)$ for specified time followed by quenching in water. The two step aging included heating to $760^{\circ} \mathrm{C}\left(1400^{\circ} \mathrm{F}\right)$ and holding for specified time, furnace cooled at $55^{\circ} \mathrm{C} / \mathrm{hr}\left(100^{\circ} \mathrm{F} / \mathrm{hr}\right)$ to $620^{\circ} \mathrm{C}\left(1148^{\circ} \mathrm{F}\right)$ and held for specified time, followed by air cooling to room temperature.

After heat treatment the disk was machined for macrostructure analysis and ultrasonic inspection. The entire surface of each of the disk faces was etched to evaluate macrostructural effects of the forging process. Following the macroetch, two independent ultrasonic inspections were carried out. Both were performed on automated inspection and data acquisition systems.

\section{Macrostructure}

\section{Results}

The entire surface of the disk was macroetched. As shown in Figure 2, there was a homogeneous structure with no macrosegregations or evidence of accelerated grain growth (AGG). Further macroetching was performed on radial sections removed for mechanical testing. These sections were parallel and transverse to strokes of final forging. and also showed a homogeneous structure. 


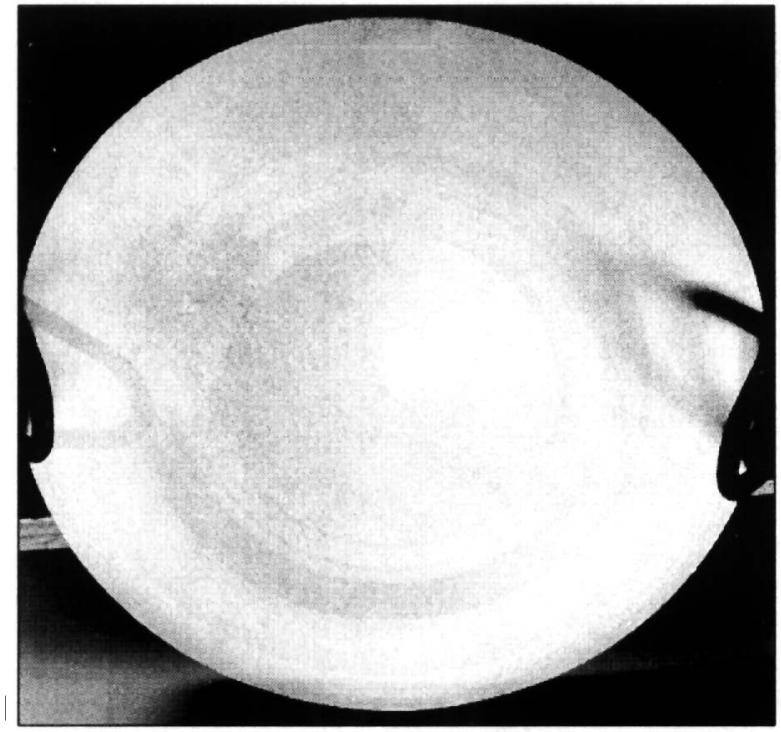

Figure 2 - Macrophoto of disk surfaced after etching

\section{Ultrasonic Testing}

The disk was $100 \%$ ultrasonic inspected using a $2 \mathrm{MHz}$ transducer. No reportable indications were found. The minimum detectable defect size (MDDS) was $1.4 \mathrm{~mm}$ (0.055 in) for the axial and $2.7 \mathrm{~mm}(0.11 \mathrm{in})$ for the radial directions.

\section{Destructive Analysis}

Figures 3 and 4 show the sectioning plan of the disk and location of test specimens within the sections. Test specimens were taken from locations parallel $(\mathrm{P})$ and transverse $(\mathrm{T})$ to the strokes of last forging pass.
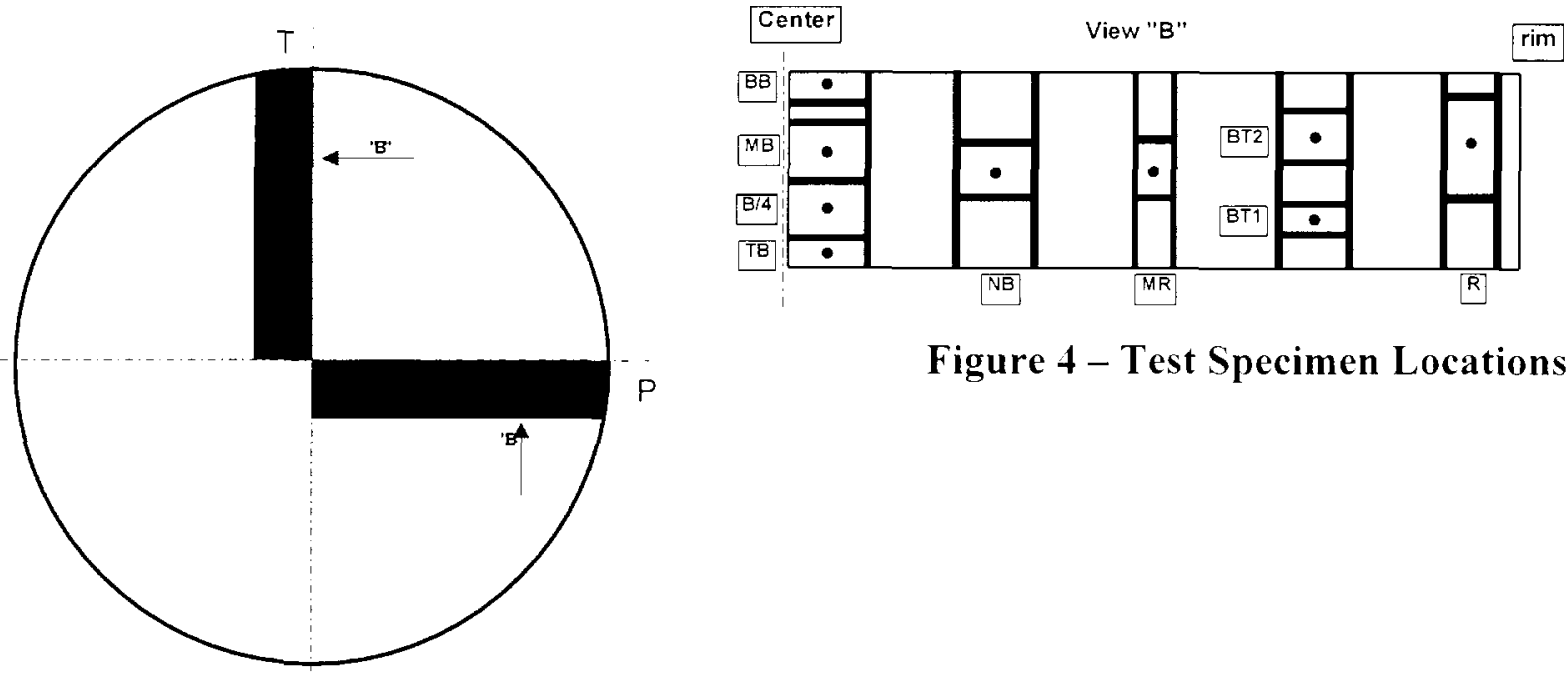

Figure 4 - Test Specimen Locations

Figure 3 - Disk Sectioning Plan 
Chemical Composition. The chemical composition of the heat analysis as well as check analyses at the rim and center positions is shown in Table 1. All analyses met requirements for composition and uniformity.

\begin{tabular}{|c|c|c|c|c|c|c|c|c|c|c|c|c|}
\hline Location & $\mathrm{C}$ & $\mathrm{Si}$ & $\mathrm{Mn}$ & $\mathrm{P}$ & $\mathrm{S}$ & $\mathrm{Al}$ & $\mathrm{B}$ & $\mathrm{Cr}$ & $\mathrm{Nb}$ & $\mathrm{Ni}$ & $\mathrm{Ti}$ & $\mathrm{Fe}$ \\
\hline heat & 0,012 & 0,05 & 0,07 & 0,007 & 0,0003 & 0,24 & 0,004 & 16 & 2,91 & 41,5 & 1,74 & bal \\
\hline Rim & 0,013 & 0,06 & 0,07 & 0,007 & 0,0005 & 0,20 & 0,004 & 16,05 & 2,89 & 41,0 & 1,69 & bal \\
\hline Center & 0,013 & 0,06 & 0,07 & 0,007 & 0,0005 & 0,18 & 0,004 & 16,05 & 2,87 & 41,0 & 1,69 & bal \\
\hline
\end{tabular}

Table 1 - Chemical Analyses

Mechanical Properties. Tensile and Charpy specimens were removed from the locations shown in Figure 2. The specimens were oriented tangentially (circumferentially) with respect to disk OD. Additional specimens with axial orientation were also taken from rim and center locations. Figures $4-6$ show a comparison of $0.2 \%$ yield, elongation, and impact at the various test locations. The charts show average of rim, mid-radius, bore and axial properties. The axial data is an average of axial tests from rim, bore and mid-radius locations.

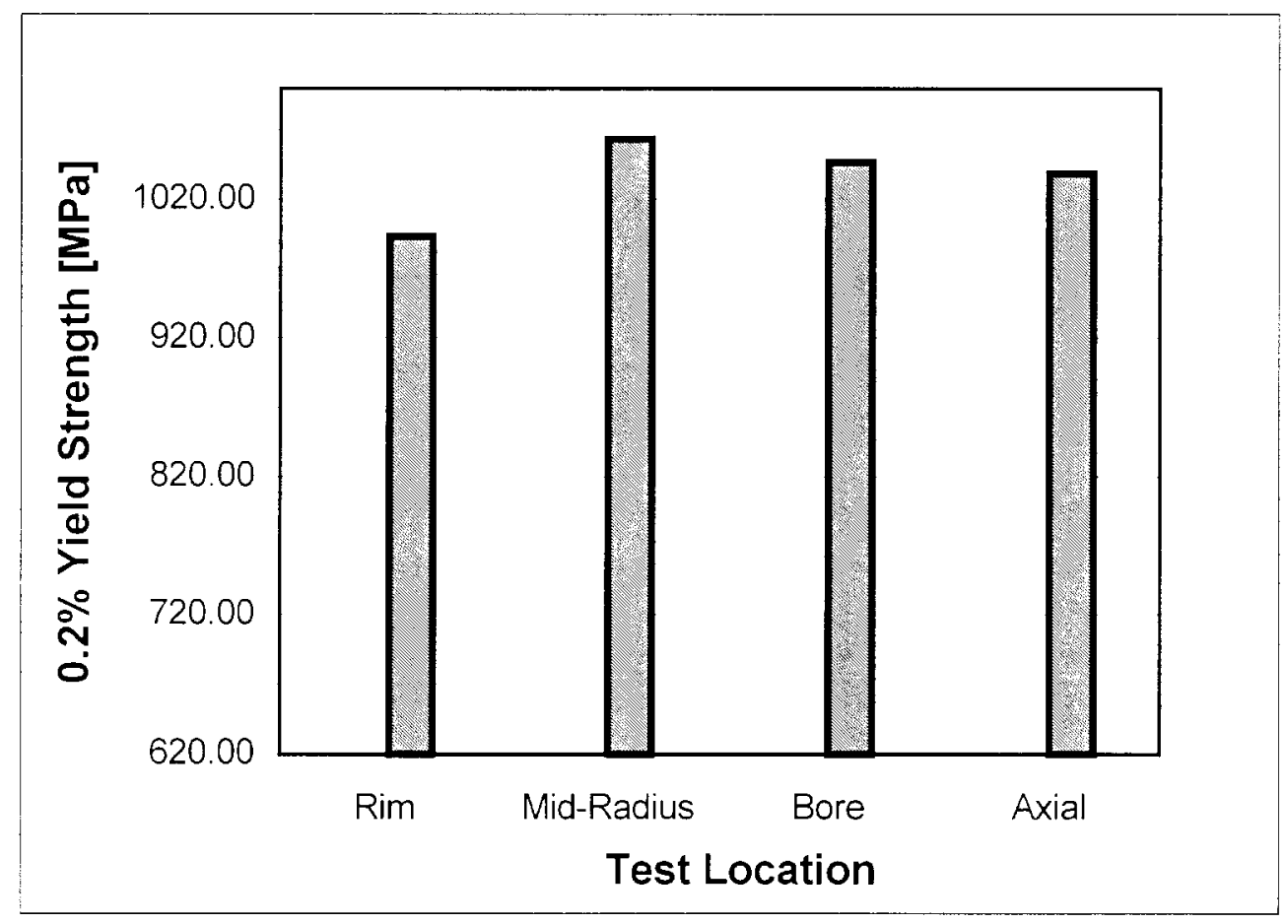

Fig. 4 Yield strength parallel and transverse to last final forging strokes (section $P$ and $T$ ) 


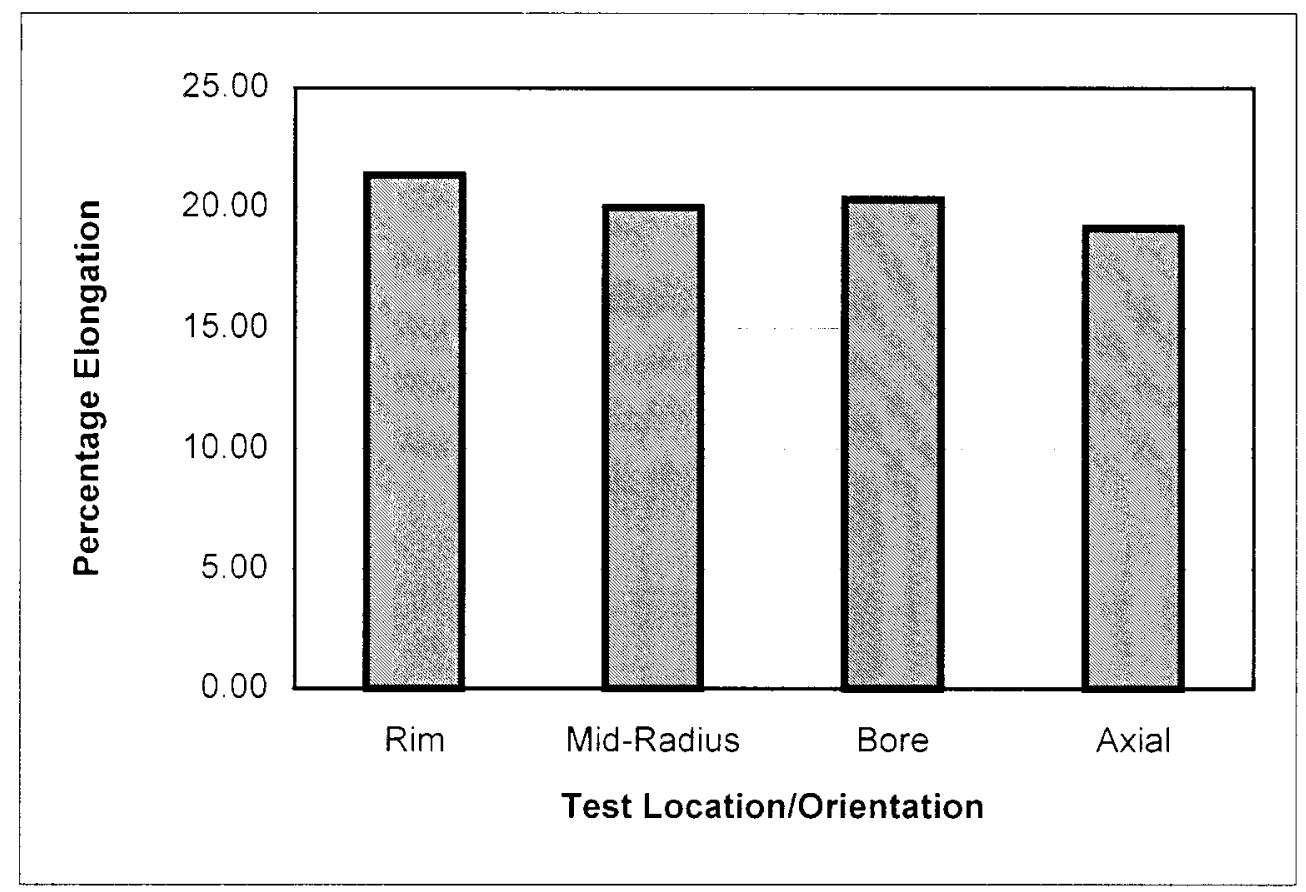

Fig. 5 Elongation parallel and transverse to last strokes of final forging (section $P$ and $T$ )

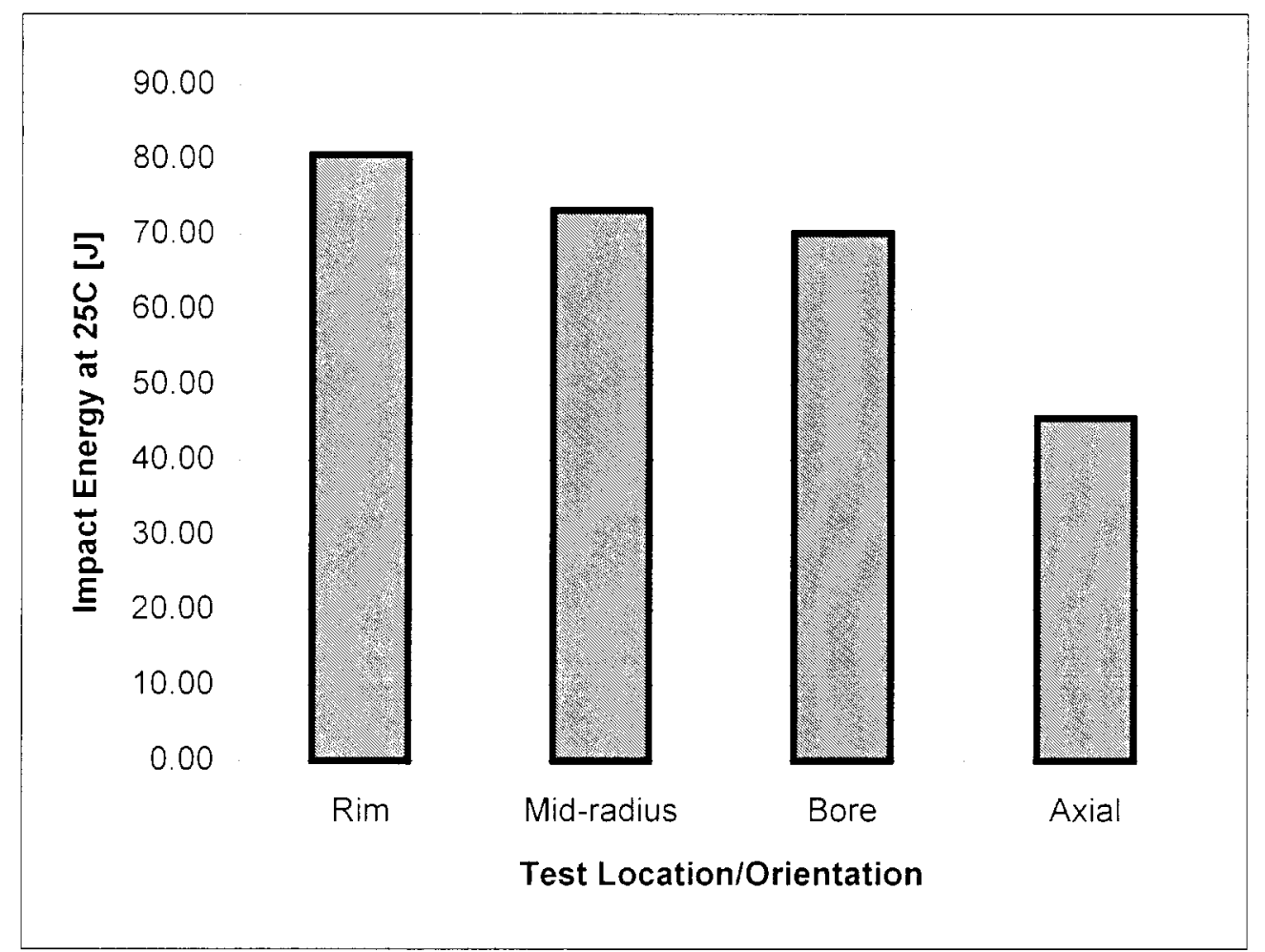

Fig. 6 Impact parallel and transverse to last strokes of final forging (section $P$ and $T$ )

Some general trends in the data were

- The yield strength at the rim was slightly lower than other locations

- There was no significant difference in vield strength between axial and tangential specimens

- The impact energy for the axial specimens were lower than those for tangential specimens

- The impact energy for rim locations were lower than the center locations 
Tensile tests were also performed at the elevated temperatures of $400^{\circ} \mathrm{C}\left(750^{\circ} \mathrm{F}\right)$ and $482^{\circ} \mathrm{C}$ $\left(900^{\circ} \mathrm{F}\right)$. The averages of all values are summarized in Figures 9 and 10. The results fell within expected range.

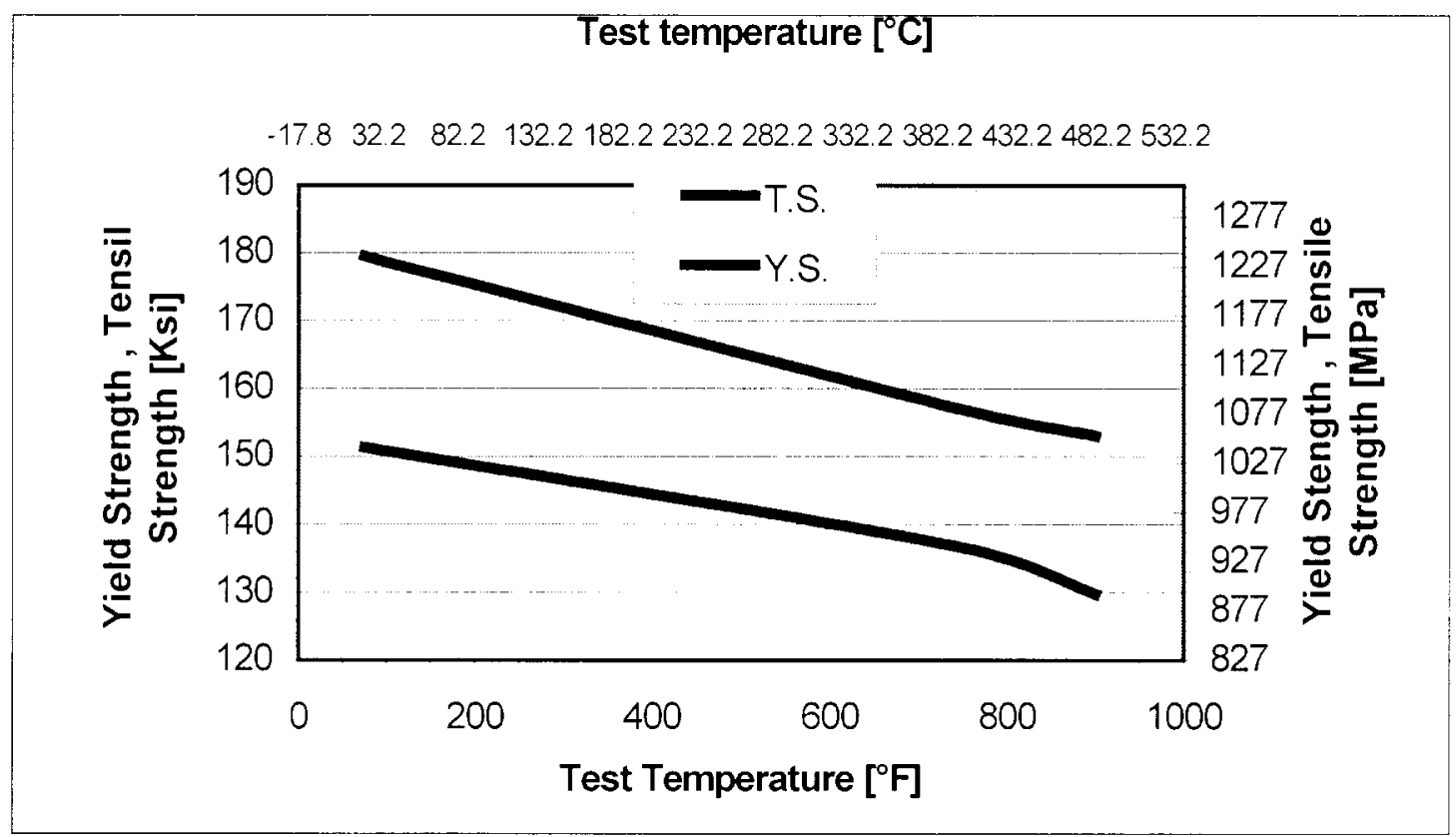

Fig. 9 Tensile properties at elevated temperatures (Yield Strength and Tensile Strength)

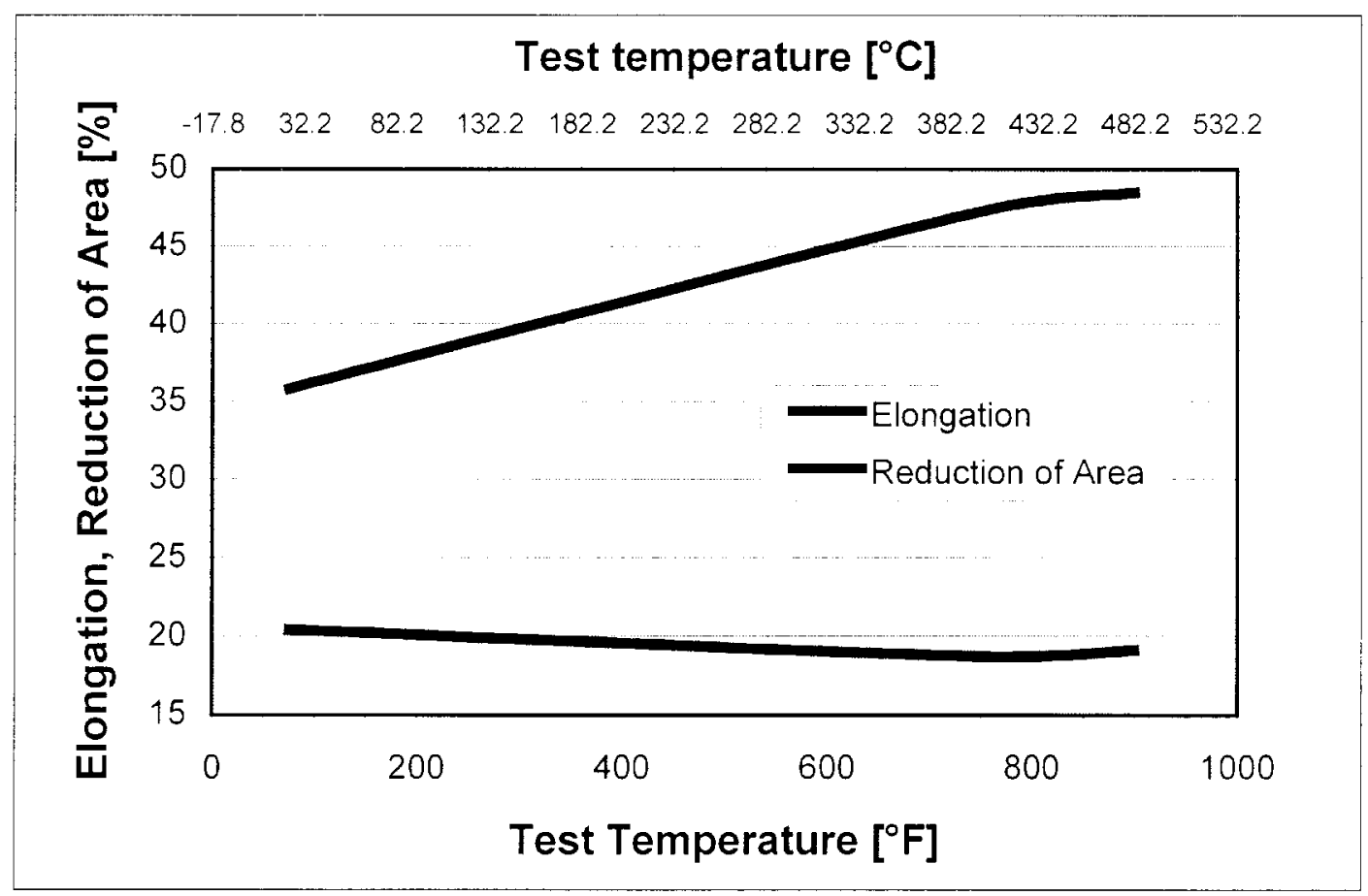

Fig. 10 Tensile properties at elevated temperatures (Elongation and Reduction of Area) 
Microstructure. Typical microstructures from R (rim), MR (mid-radius), and MB (center) are shown in Figure 11. The average grain size was determined to be ASTM 3.5 to 4.5 .

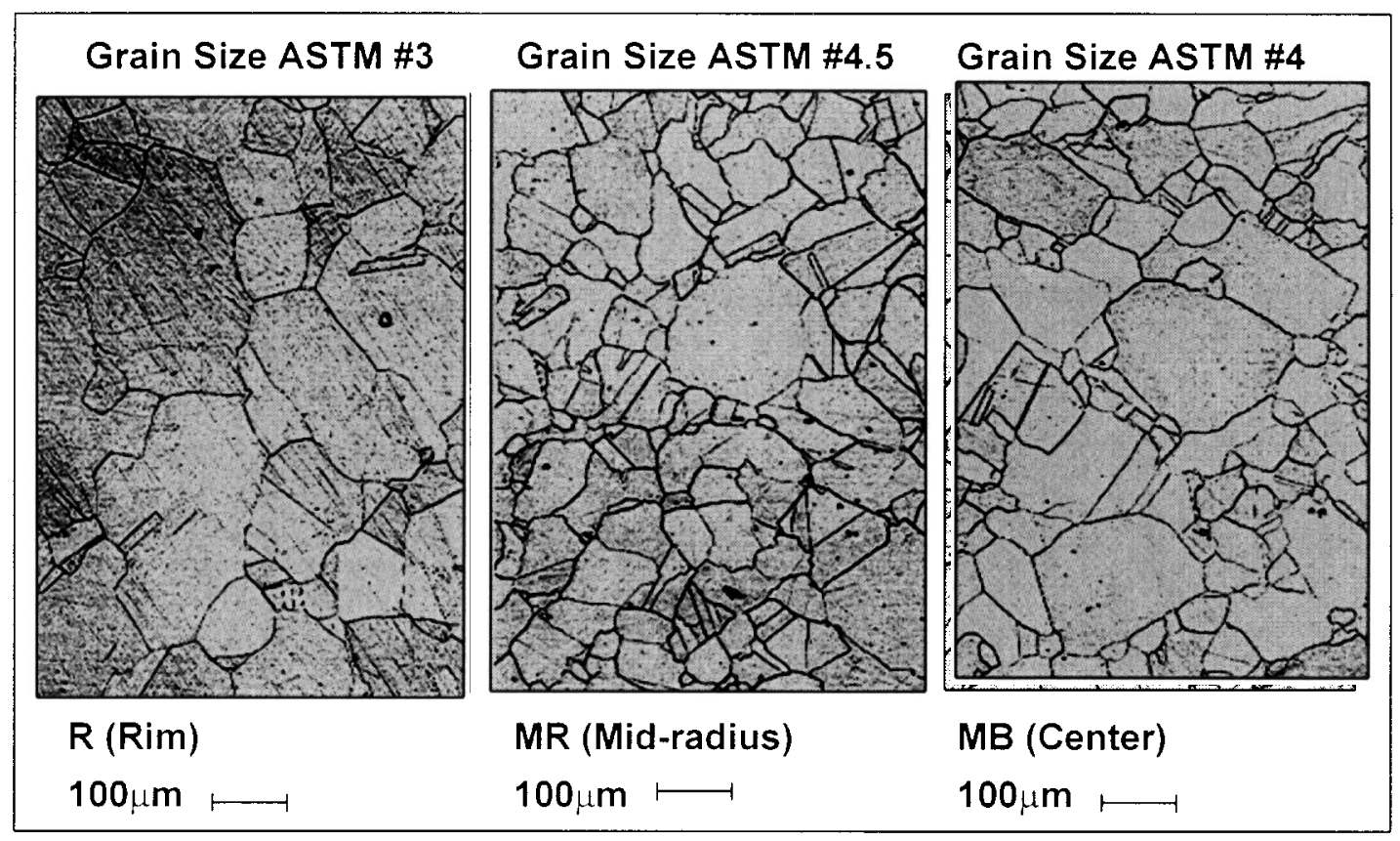

Fig. 11 Photomicrographs showing representative structure from various test locations

\section{Discussion}

Traditionally superalloy forgings for gas turbine rotor parts are made by closed die forging. The reason is that microstructure development in superalloys is a function of strain-strain ratetemperature history. A closed die process is more likely to produce a more uniform and axisymmetric pattern. The mechanical properties are a function of final microstructure and the rotor applications require axis-symmetric properties. The open die process by definition cannot be axi-symmetric. Alloy 706 in this process is given a super solvus heat treatment to get full thermal recrystallization. The grain size produced on super-solvus thermal recrystallization is usually a function of the temperature. A minimum prior strain is needed to initiate and complete re-crystallization. As long as this minimum is reached in all areas of the forging it is possible to achieve a uniform recrystallized grain size. This minimum strain has been identified in the case of Alloy $706^{4}$ and it has been found that any variation in strain above the minimum has little or no effect on final grain size.

There are some critical steps to be considered in the use of open die forging of such parts. The first is to ensure that each location achieves a minimum cumulative strain at all locations so that full recrystallization would occur at the next re-heat. The second is to ensure that the process is repeatable. Repeatability includes temperatures, transfer times, strokes, bites and re-heat times. In this sense the open-die forging process for superalloys is more complex and has to have some degree of automation.

The above results have shown that with proper control of the process it is possible to achieve a uniform grain structure and mechanical properties in large Alloy 706 forgings . 


\section{Conclusions}

- The open die forging process produced forging which met mechanical, grain size and sonic requirements expected for closed die forging.

- There was no significant difference in measured properties between sections parallel and transverse to final forge pass.

- There was no significant difference in measured properties in test specimens axial and transverse orientations

- The process variation in open die forging process should be further evaluated.

\section{References}

(1) P.W. Schilke et al, Advanced Materials Propel Progress in Land-based Gas Turbines, Advanced Materials and Progress, 4 (1992), page 22-30.

(2) S.V. Thamboo, L. Yang, R.C. Schwant, Large Forgings of Alloy 706 and Alloy 718 for Land-based Gas Turbines, $14^{\text {th }}$ International Forgemasters Meeting, Wiesbaden, Germany, September 2000, pages 330-335

(3) D. Rayne, J.F. Uginet, Fabrication of Large Components in 706 Alloy for Gas Turbine Application, $11^{\text {th }}$ International Forgemasters Meeting, Terni/Spoleto, Italy, 1991

(4) S.V. Thamboo, Thermomechanical Behavior and Microstructure Development of Alloy 706. Superalloy 718,625,706 and Various Derivatives, TMS 1997, pages 211-217 